\title{
Análise cognitiva da letra de canção "Pelas esquinas da nossa casa", de Roberto e Erasmo Carlos: o papel dos frames na construção de sentidos $^{1}$
}

\section{L'analyse cognitive de la parole "Pelas esquinas da nossa casa", de Roberto e Erasmo Carlos: le rôle des frames dans la construction des sens}

Ilana Souto Medeiros ${ }^{2}$

DOI: $10.28998 / 2317-9945.2020 n 64 p 133-143$

\section{Resumo}

Este artigo, inserido no escopo teórico da Linguistica Cognitiva (LC), pretende evidenciar o modo pelo qual mecanismos cognitivos, como os frames, influenciam a construção de sentidos. Para esse fim, discorremos sobre um dos princípios fundantes da LC, o de corporalidade, apresentamos a noção de frame que subsidia teórica e metodologicamente este estudo e delimitamos nossas categorias de análise: frames conceptuais básicos $e$ frame roteiro (DUQUE, 2015). Quanto aos aspectos metodológicos, a pesquisa em tela é de caráter qualitativo, posto que não faz uso de representações numéricas nem de quantificação de valores (SILVEIRA; CÓRDOV A, 2009); adota a metodologia de frames aplicada ao discurso (DUQUE, 2015), que nos permite identificar as variadas dimensões constituintes do frame; e utiliza, como corpus, a letra de canção "Pelas esquinas da nossa casa", composta por Roberto e Erasmo Carlos na década de 1980. Os resultados obtidos sugerem que os frames, quando acionados, constroem uma rede de significados a partir da qual sentidos diversos podem ser depreendidos.

Palavras-chave: Construção de sentidos. Letra de canção. Frames.

\section{Résumé}

Cet article est basé sur la Linguistique Cognitive (LC) et il vise à démontrer la manière dont des mécanismes cognitifs, comme les frames, influencent la construction des sens. Pour cela, nous présentons un des plus importants principes de la LC, la corporalité, nous montrons la notion de frame qui subventionne théorique et méthodologiquement cette étude et nous définissons notre catégorie analytique: les frames conceptuels basiques et le frame scenario (DUQUE, 2015). En ce qui concerne les aspects méthodologiques, cette recherche est qualitative, puisqu'elle ne fait pas usage de représentations numériques ni de quantification de valeurs (SILVEIRA; CÓRDOVA, 2009); elle adopte la méthodologie de frames appliquée au discours (DUQUE, 2015) qui nous permet d'identifier les plusieurs dimensions constituantes du frame; et elle utilise, comme corpus, la parole "Pelas esquinas da nossa casa", écrite par Roberto e Erasmo Carlos dans les années 1980. Les résultats obtenus suggèrent que les frames, une fois actionnés, construisent un réseau de significations à partir duquel plusieurs sens peuvent être inférés.

Mots-clés: Construction de sens. Parole. Frames.

\footnotetext{
${ }^{1}$ O presente trabalho foi realizado com o apoio da Coordenação de Aperfeiçoamento de Pessoal de Nível Superior - Brasil (CAPES) - Código de Financiamento 001.

${ }^{2}$ Doutoranda e Mestra pelo Programa de Pós-graduação em Estudos da Linguagem da Universidade Federal do Rio Grande do Norte.
} 
Recebido em: 08/05/2019.

Aceito em: 03/07/2019.

\section{Introdução}

Este estudo, inserido no escopo teórico da Linguística Cognitiva de base corporificada, tem, como principal objetivo, demonstrar como mecanismos cognitivos, a exemplo dos frames, participam do processo de construção de sentidos. Para tal fim, discorre sobre um dos princípios fundantes da LC, o conceito de corporalidade; apresenta a noção de frame que o norteia teórica e metodologicamente; e circunscreve as categorias de análise que serão exploradas: frames conceptuais básicos e frame roteiro (DUQUE, 2015).

No que concerne aos aspectos metodológicos, se configura como uma pesquisa de natureza qualitativa, dado que, para proceder à investigação de um determinado fenômeno, como a construção de sentidos, não necessita recorrer a representatividades ou a quantificações numéricas (SILVEIRA; CÓRDOVA, 2009); e utiliza, como corpus, a letra de canção "Pelas esquinas da nossa casa", composta por Roberto e Erasmo Carlos na década de 1980.

O critério adotado para a escolha do corpus foi metodológico, tendo em vista que as categorias de análise selecionadas para a realização deste trabalho, frames conceptuais básicos e frame roteiro, são bastante evidenciadas na letra supracitada. Diante disso, acessamos um conhecido site de letras de canções para extraí-la e exibi-la na seção dedicada à análise.

Quanto aos procedimentos de análise, apresentamos o texto completo da letra e, a partir de seus fragmentos, que foram enumerados em algarismos arábicos, discorremos sobre como as pistas linguísticas acionam frames e como os frames constroem sentidos.

\section{Corporalidade}

O conceito de corporalidade, um dos princípios fundantes da LC, surgiu no século XX e foi explorado pela Fenomenologia Hermenêutica, a partir do pensamento do filósofo Paul Ricoeur, pelo Pragmatismo americano, com as discussões propostas por William James e John Dewey, e pela Fenomenologia, com o pensamento do filósofo francês Maurice Merleau-Ponty. Tal conceito, oportuno ressaltar, rompeu com as abordagens dualistas, segundo as quais a mente é vista como um módulo autônomo e independente do corpo.

Paul Ricoeur, um dos primeiros a criticar essa visão, concebeu a linguagem como "[...] uma abertura, uma mediação para a compreensão da experiência humana" (MENDES, 2012, p. 8). Nesse sentido, o filósofo francês sugeriu que o corpo não é uma entidade independente, mas, ao contrário, é compreendido como um fato do mundo (RICOEUR, 1990).

A abordagem naturalista da pragmática, delineada com base no pensamento de James e Dewey, também diverge do dualismo epistemológico mente/corpo. Consoante essa perspectiva, nossa racionalidade emerge e é formada pela natureza de nossos corpos, o que evidencia o fato de que "[...] a mente nunca está separada do corpo, pois há sempre uma série 
de atividades corpóreas imersas no fluxo contínuo de interações organismo-ambiente que constitui a experiência" (JOHNSON; ROHRER, 2007, p. 5 [tradução nossa] ${ }^{3}$ ).

Ancorado a uma linha de raciocínio similar à de James e Dewey, Maurice MerleauPonty também chamou a atenção para a íntima relação entre o corpo e a linguagem. Em uma de suas obras mais conhecidas, Phénoménologie de la Perception ${ }^{4}$, o fenomenólogo reconhece essa noção a partir de inúmeras afirmações, dentre as quais destacamos:

[...] meu corpo não é apenas um objeto entre tantos outros, um complexo de qualidades entre outros, ele é um objeto sensivel a todos os outros, que ressoa para todos os sons, vibra para todas as cores, e que fornece às palavras a sua significação primordial por meio do modo pelo qual ele as acolhe (MERLEAU-PONTY, 1945, p. 290 [grifo do autor] [tradução nossa $]^{5}$.

Em outra obra, Le Visible et L'invisible, ${ }^{6}$ Merleau-Ponty também chama a atenção para a existência de uma conexão entre o corpo e o mundo. Segundo ele, "[...] entre esses dois seres verticais não há uma fronteira, mas uma superfície de contato" (1964, p. 318 [tradução nossa $]^{7}$ ). Em linhas gerais, o fenomenólogo parece apontar para uma relação de interdependência entre corpo, linguagem e ambiente.

As ideias de James, Dewey e Merleau-Ponty, com relação à corporalidade, fundamentaram a noção de realismo experiencial que, grosso modo, afirma que nossa percepção da realidade externa é moldada por meio de nossos corpos. Em outras palavras, como aponta Evans (2012), as particularidades da nossa configuração corpórea e da nossa arquitetura neuroanatômica, enquanto seres humanos, nos fornecem uma visão de mundo específica e distinta das demais espécies.

Um modo de perceber como a corporalidade influencia as experiências pode ser visto na gravidade. Evans e Green (2006), a título de exemplo, comparam a maneira como os colibris, os seres humanos e os peixes interagem com essa característica do mundo.

Para superar a gravidade, segundo os autores, um colibri, que pode bater suas asas 50 (cinquenta) vezes por segundo, é capaz de se projetar no ar sem empurrar o solo, graças ao rápido movimento realizado por suas asas - algo impossível para um ser humano. Os peixes, por sua vez, pouco interagem com a gravidade, visto que a água reduz seu efeito.

Outro aspecto intrínseco ao conceito de corporalidade diz respeito ao modo como organizamos, cognitivamente, as experiências que emergem de nossa interação com os entornos ambiental, social e cultural. Diante disso, abordaremos, na seção seguinte, a noção de frames: mecanismos cognitivos que abrangem desde informações básicas, como as associadas à nossa configuração corpórea, até experiências mais complexas, relacionadas a elementos culturais.

\footnotetext{
3 "On this view, mind is never separate from body, for it is always a series of bodily activities immersed in the ongoing flow of organism-environment interactions that constitutes experience".

${ }^{4}$ Fenomenologia da Percepção [tradução nossa].

5 “[...] mon corps n'est pas seulement un objet parmi tous les autres objets, un complexe de qualités sensibles parmi d'autres, il est un objet sensible à tous les autres, qui résonne pour tous les sons, vibre pour toutes les couleurs, et qui fournit aux mots leur signification primordiale par la manière dont il les accueille".

${ }^{6} \mathrm{O}$ Visível e o Invisível [tradução nossa].

7 "Et entre ces deux êtres verticaux, il y a, non pas une frontière, mais une surface de contact".
} 


\section{Frames}

Tradicionalmente, grande parte da semântica clássica, sob influência dos princípios objetivistas, concebeu o significado como sendo algo exclusivamente da língua e, por essa razão, distinto de outros tipos de conhecimento. Essa perspectiva, como ressaltam Evans e Green (2006),

[...] trata o conhecimento do significado da palavra como distinto dos conhecimentos cultural e social (nossa experiência e interação com os outros) e do conhecimento físico (nossa experiência de interação com o mundo). Uma consequência dessa visão é que o conhecimento semântico é tido como autônomo dos outros tipos de conhecimento e armazenado em nosso repositório mental (EVANS; GREEN, 2006, p. 209 [tradução nossa $\left.\left.{ }^{8}\right]\right)$.

Tal pensamento, princípio fundante das abordagens definicionais, assume que o significado central de uma palavra corresponde à informação contida em sua definição, isto é, ele "[...] é modelado em termos de traços semânticos [...]" (EVANS; GREEN, 2006, p. 208 [tradução nossa $]^{9}$ ). Nesse sentido os significados das palavras equivaleriam às definições que encontramos nos dicionários.

Esse paradigma passou a ser questionado na década de 1970, com o surgimento da Semântica Cognitiva. Uma das principais críticas feitas por essa nova proposta diz respeito ao fato de que, nas perspectivas tradicionais, definições estritas " [...] não conseguem capturar adequadamente a gama e a diversidade de significados associados a um determinado conceito lexical", o que significa que "[...] as palavras não representam simplesmente pacotes de significados, mas servem como 'pontos de acesso' para o vasto repositório de conhecimento relacionados a um conceito particular [...]" (EVANS; GREEN, 2006, p. 160 [tradução nossa $]^{10}$ ). Com essa ruptura de paradigma, a partir da qual o significado deixa de ser visto como definicional e passa a ser compreendido como conceptual, surge a noção de frames.

Embora tenhamos consciência de que o conceito de frame é explorado por diversas áreas, como a Psicologia, a Antropologia, a Inteligência Artificial, entre outras, o abordaremos apenas sob a luz da Linguística, especificamente da Linguística Cognitiva. Desse modo, apresentaremos, nos parágrafos seguintes, a visão de frames que respalda teórica e metodologicamente este artigo.

Conforme Duque $(2015,2017)$, os frames são mecanismos cognitivos que podem ser compreendidos como circuitos neurais ativados e acionados pela linguagem, por meio dos quais organizamos pensamentos, ideias e visões de mundo. De acordo com o linguista, frames são ativados por estratégias como a seleção do léxico, o arranjo gramatical e o mapeamento metafórico.

Em um de seus trabalhos, Discurso e cognição: uma abordagem baseada em frames, o autor propõe uma metodologia de frames aplicada ao discurso, a partir da qual é possível verificar

\footnotetext{
8 “ [...] the dictionary view treats knowledge of word meaning as distinct from cultural knowledge, social knowledge (our experience of and interaction with others) and physical knowledge (our experience of interaction with the world). [...] a consequence of this view is that semantic knowledge is autonomous from other kinds of knowledge, and is stored in its own mental repositor [...]".

9 “" $[.$.$] word meaning is modelled in terms of semantic features [\ldots]$ "..

10 " [...] strict definitions [...] fail to adequately capture the range and diversity of meaning associated with any given lexical concept. [...] words do not represent neatly packaged bundles of meaning [...] but serve as 'points of access' to vaste repositories of knowledge relating to a particular concept [...]".
} 
esses mecanismos sob variados ângulos. Para tanto, Duque (2015) divide os frames nas dimensões ${ }^{11}$ cognitiva: frame conceptual básico, frame descritor de evento, frame roteiro, frame esquema-I, frame social, frame de domínio específico e frame cultural; e interacional: frame interacional.

Como previsto, discutiremos, neste artigo, sobre os frames conceptuais básicos e sobre o frame roteiro. Contudo, cumpre salientar que um frame, quando ativado, é capaz de evocar, simultaneamente, outros tipos de frames - o que constrói uma rede de significados. Esse entendimento fortalece a ideia de que o cérebro humano é visto como um sistema de neurônios intrinsecamente interligados (FELDMAN, 2006), ou, como afirmam Lakoff e Wehling, que ele é estruturado em cascata, ou seja, "[...] uma rede de neurônios que liga vários circuitos cerebrais" (2012, p. 28 [tradução nossa] $]^{12}$ ).

\section{Frame conceptual básico}

Frames conceptuais básicos, de acordo com Duque (2015), são acionados por meio de itens e/ou expressões individuais. No nível do discurso, esses frames são linguisticamente instanciados por substantivos e expressões nominais, que recuperam as experiências arquivadas na região sensorial do nosso cérebro.

Outra característica associada aos conceptuais básicos reside no fato de que palavras simples são capazes de evocar um frame completo "[...] sem que seja necessário apresentar um conjunto exaustivo de itens e expressões lexicais" (DUQUE, 2015, p. 33).

A título de exemplo, consideremos o frame $\mathrm{FUTEBOL}^{13}$. Nele, estão armazenadas todas as experiências que cada pessoa possui com relação a esse esporte: desde informações básicas, como associá-lo a uma bola, a um árbitro, a 11 jogadores, entre outras; a informações que envolvem determinadas ações, como a compra do ingresso, o trajeto feito até o local do jogo etc.

Oportuno assinalar que um frame dessa natureza será mais ou menos refinado de acordo com as experiências dos sujeitos. Ou seja, o frame FUTEBOL, acionado por um jogador de futebol, terá uma variedade maior de informações se comparado àquele acionado por alguém que conheça minimamente o esporte, como ilustra a figura 1.

\footnotetext{
${ }^{11}$ É válido destacar que a divisão entre as dimensões cognitiva e interacional é feita unicamente com base em critérios didáticos, pois, segundo o linguista, elementos cognitivos perpassam os frames interacionais e viceversa.

12 "A cascade is a network of neurons that links many brain circuits".

${ }^{13}$ De acordo com a perspectiva teórica adotada neste artigo, baseada em notação utilizada por Duque (2015), frames são grafados em caixa alta e fonte 9 .
} 
Figura 1 - Alguns dos constituintes do frame conceptual básico FUTEBOL

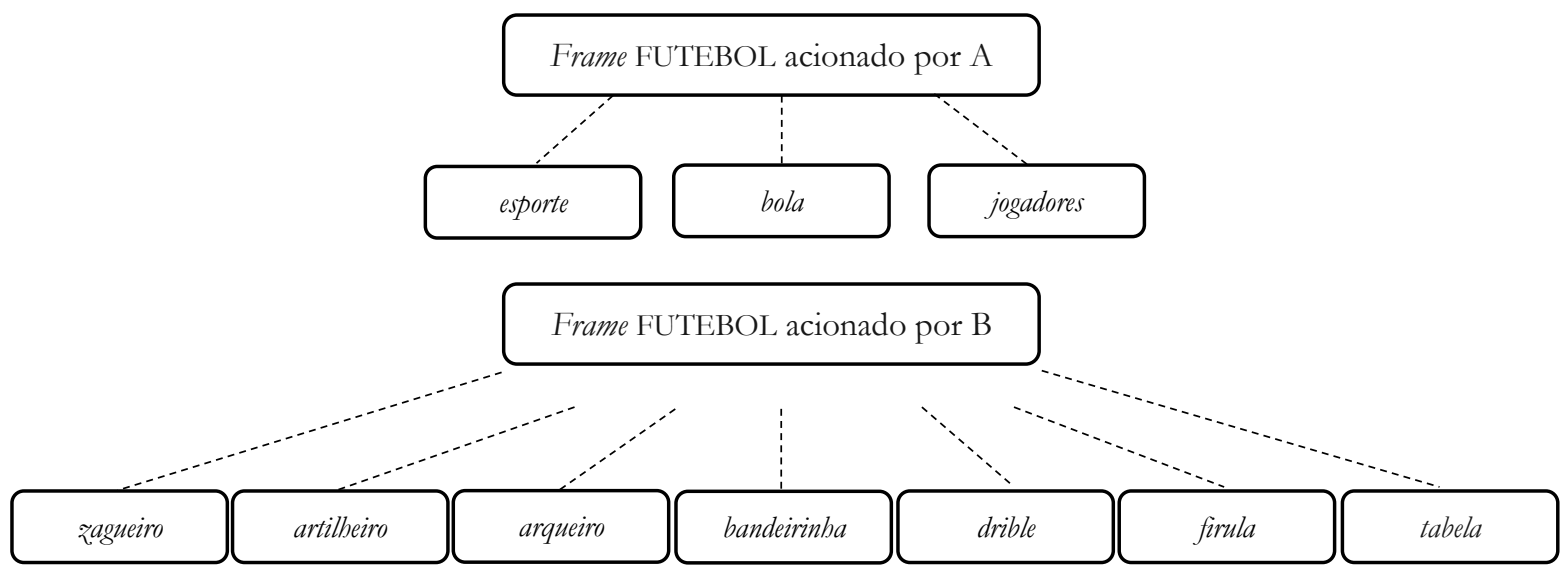

Fonte: elaborada pela autora.

Notamos, na figura 1, que um mesmo item lexical, como "futebol", pode recuperar determinados constituintes do frame conceptual básico FUTEBOL. A quantidade de informações que compõe esse frame, como dissemos, depende das experiências individuais de cada um no que se refere, nesse caso, ao futebol. Nesse sentido, o frame FUTEBOL, quando acionado por alguém que não conheça profundamente esse esporte, provavelmente será formado por informações mais gerais que normalmente são reconhecidas pelo senso comum, como "esporte", "bola" e "jogadores", por exemplo. Por outro lado, o mesmo frame, acionado por um jogador experiente ou por um conhecedor de futebol, possivelmente evocará elementos bastante específicos, como "zagueiro", "artilheiro", "arqueiro", "bandeirinha", "drible", "firula", "tabela", entre outros.

\section{Frame roteiro}

O frame roteiro, por meio do qual é possível identificar um conjunto de eventos, é caracterizado pela cristalização, em uma dada cultura, de uma sequência de ações envolvidas nos mais variados eventos. Duque $(2015$, p. 39$)$ esclarece essa ideia ao afirmar que "[...] a experiência recorrente de um determinado evento pode criar um molde internalizado da provável sequência de ações, participantes e entidades dentro da situação experienciada".

Um exemplo de como os roteiros são socialmente internalizados pode ser observado no frame CASAMENTO. Em muitos países, sobretudo no Brasil, a cerimônia do casamento é composta por uma sequência de ações executadas por participantes específicos. Dito de outro modo, sabemos que, normalmente, iremos presenciar, em um evento desse tipo, uma cadeia de etapas, como a entrada dos padrinhos, dos noivos, a troca das alianças, a bênção de um religioso, o momento do "sim", dentre outras.

Em outras culturas, entretanto, o roteiro CASAMENTO pode ser constituído por determinadas ações que não fazem parte daquilo que consideramos prototípico. $\mathrm{Na}$ Grécia, por exemplo, é comum a quebra de pratos para desejar sorte aos noivos; na Índia, durante a cerimônia, as mãos e os pés da noiva são tatuados; na Rússia, após beber champanhe, os convidados atiram as taças no chão como forma de desejar sorte ao casal; e assim por diante. 
$\mathrm{Na}$ seção seguinte, dedicada à análise do corpus, mostraremos, por meio da letra de canção "Pelas esquinas da nossa casa", composta por Roberto e Erasmo Carlos na década de 1980, o acionamento de um frame roteiro, assim como o de um frame conceptual básico.

\section{Análise e discussão}

Antes de proceder à análise da letra de canção, julgamos importante contextualizá-la brevemente. A partir de sua leitura, inferimos que a letra faz menção a um casal apaixonado que se desloca por algumas partes de uma casa. Nesse trajeto, o casal troca carícias e chega a um quarto, onde provavelmente farão amor.

Pelas esquinas da nossa casa ${ }^{14}$ - Roberto e Erasmo Carlos

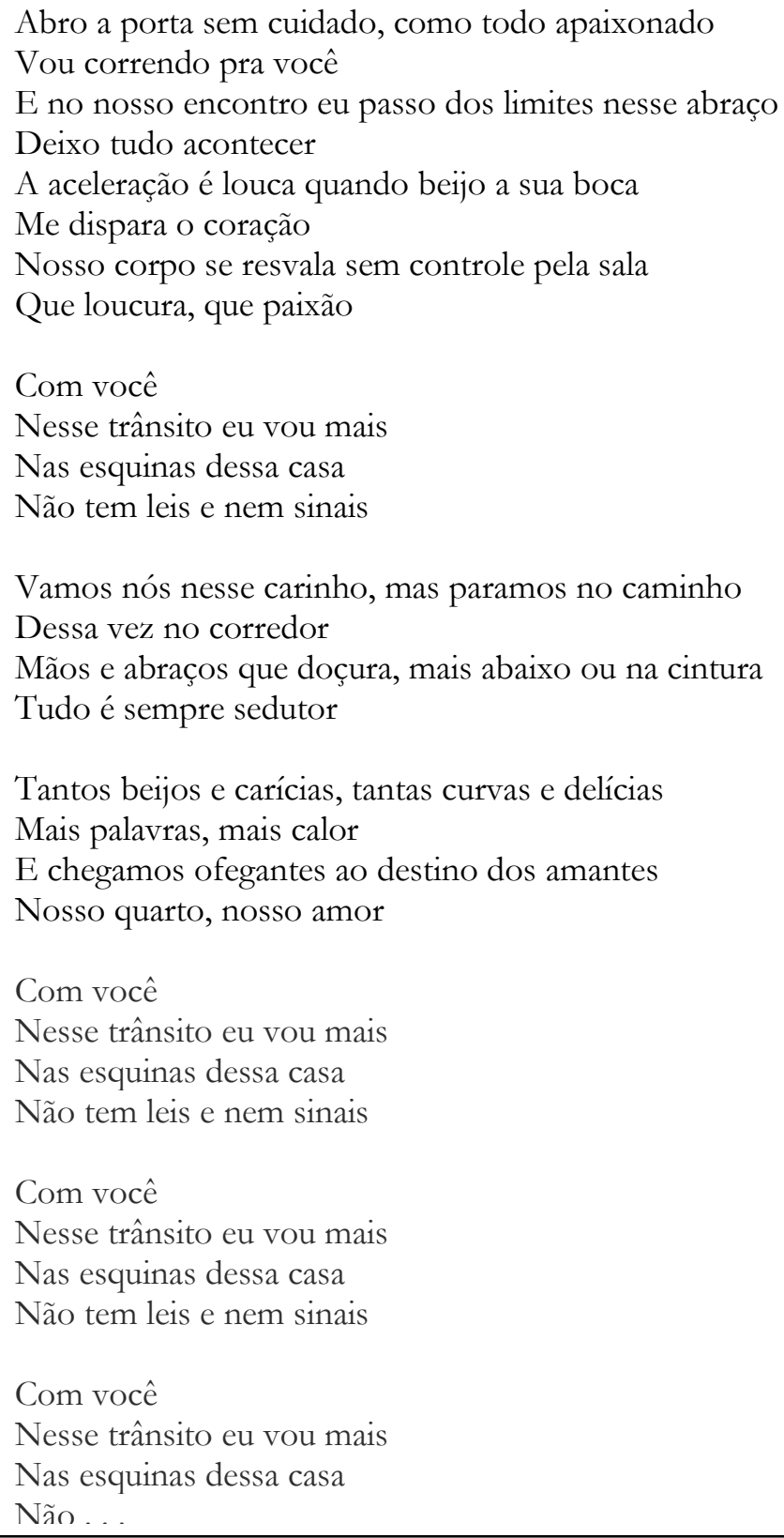

14 Letra de canção extraída em: https://www.vagalume.com.br/roberto-carlos/pelas-esquinas-da-nossacasa.html. Acesso em: 15 jul. 2019. 
Com base nos insumos linguísticos disponíveis na letra, inferimos o acionamento de três frames conceptuais básicos (CASAL, CASA e QUARTO) e do frame roteiro PREPARAÇÃO PARA O ATO SEXUAL. Vejamos com mais detalhes, a seguir, cada um deles.

Frame conceptual básico CASAL

(1) "Abro a porta sem cuidado, como todo apaixonado / Vou correndo pra você / E no nosso encontro eu passo dos limites nesse abraço / Deixo tudo acontecer" (grifos nossos).

(2) "A aceleração é louca quando beijo sua boca / Me dispara o coração / Nosso corpo se resvala sem controle pela sala / Que loucura, que paixão" (grifos nossos).

(3) "Vamos nós nesse carinho, mas paramos no caminho [...]" (grifo nosso).

Verificamos que os itens destacados nos fragmentos expressos em (1), (2) e (3) estão associados a duas pessoas. Nos primeiros versos da letra, sobretudo graças às expressões "nosso encontro" e "nesse abraço", em (1), isso pode ser constatado por duas razões, quais

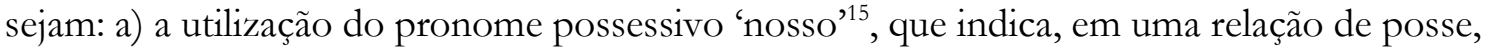
a presença de mais um possuidor; e b) o uso do substantivo 'abraço', empregado para denotar uma demonstração de afeto própria dos humanos. Outras pistas que nos permitem construir tal inferência são observadas em (2), nas expressões "sua boca" e "nosso corpo", e em (3), com o auxílio do item "nós".

Ademais, o material linguístico destacado nos fragmentos nos leva a inferir que os sujeitos evocados na letra formam um casal, pois os itens "apaixonado", em (1), e "paixão", em (2), fazem referência ao forte sentimento de atração que pode existir entre duas pessoas.

Observamos, também em (2), que outro indexador pode nos auxiliar a refinar os sentidos que vão sendo construídos a partir da leitura da letra. Trata-se do item "sala", que mostra o casal a partir de outra perspectiva: a do local onde se encontra. Esse mesmo item, como veremos a seguir, aciona o frame conceptual básico CASA.

Frame conceptual básico CASA

Como dissemos anteriormente, o item "sala", verificado em (2), parece ser responsável pelo acionamento do frame CASA, que está relacionado ao lugar onde o casal parece estar. Ao longo da letra, notamos, por intermédio dos itens destacados em (4), (5) e (6), que essa inferência se confirma:

(4) "Com você / Nesse trânsito eu vou mais / Nas esquinas dessa casa / Não tem leis e nem sinais" (grifo nosso).

(5) "Vamos nós nesse carinho, mas paramos no caminho / Dessa vez no corredor [...]" (grifo nosso).

(6) "E chegamos ofegantes ao destino dos amantes / Nosso quarto, nosso amor" (grifo nosso).

O substantivo 'casa', em (4), indexa linguisticamente o frame CASA e sugere o local onde o casal parece estar. Já os itens "corredor", em (5), e "quarto", em (6), focalizam

${ }^{15}$ Conforme notação utilizada por Duque (2015), formas linguísticas, como substantivos, verbos, pronomes, dentre outras, são grafadas entre aspas simples. 
componentes específicos desse frame. Percebemos, além disso, que a expressão de posse indicada pelo pronome 'nosso', em "nosso quarto", acrescenta o sentido de um lar ao frame CASA.

Com base nos versos descritos em (4), (5) e em (6), observamos que o casal realiza uma pequena trajetória dentro da casa onde se encontra. Esse deslocamento, que se inicia na sala ("Abro a porta sem cuidado [...] / vou correndo pra você [...] / Nosso corpo se resvala sem controle pela sala [...]"), termina no quarto ("E chegamos ofegantes [...] / Nosso quarto [...]"). O item lexical "quarto", diante disso, cria expectativas em relação ao que acontecerá com o casal após chegar a seu destino, e, ademais, aciona outro frame conceptual básico: QUARTO.

Frame conceptual básico QUARTO

O frame QUARTO, na letra de canção "pelas esquinas da nossa casa", é linguisticamente instanciado pelas expressões "destino dos amantes" e "nosso quarto", realçadas em (7).

(7) "Tantos beijos e carícias, tantas curvas e delícias / Mais palavras, mais calor / E chegamos ofegantes ao destino dos amantes / Nosso quarto, nosso amor" (grifos nossos).

Essas duas expressões, como mostra o fragmento, focalizam um componente específico do frame CASA, o quarto. Também verificamos que uma delas, "destino dos amantes", é capaz de evocar não apenas um dos cômodos de uma casa, mas também, o local onde, normalmente, os casais têm relações sexuais. Outras evidências linguísticas que constroem esse sentido podem ser identificadas, em (7), pelos itens "beijos", "carícias", "delícias" e "ofegantes". Com a descrição do frame roteiro PREPARAÇÃO PARA O ATO SEXUAL, que será feita a seguir, será possível perceber a legitimação dessa inferência.

Frame roteiro PREPARAÇÃO PARA O ATO SEXUAL

O frame roteiro PREPARAÇÃO PARA O ATO SEXUAL, nessa letra de canção, é composto por uma sequência de eventos menores que correspondem ao deslocamento físico realizado pelo casal durante os momentos que antecedem à relação sexual. Linguisticamente, esse frame é indexado pelas ações destacadas nos fragmentos expressos em (8), (9) e (10).

(8) "Abro a porta sem cuidado, como todo apaixonado / Vou correndo pra você / E no nosso encontro eu passo dos limites nesse abraço / Deixo tudo acontecer [...] / Nosso corpo se resvala sem controle pela sala / Que loucura, que paixão" (grifos nossos).

(9) "Vamos nós nesse carinho, mas paramos no caminho / Dessa vez no corredor / Mãos e abraços que doçura, mais abaixo ou na cintura / Tudo é sempre sedutor" (grifo nosso).

(10) "E chegamos ofegantes ao destino dos amantes / Nosso quarto, nosso amor" (grifo nosso).

As primeiras ações associadas ao frame roteiro supracitado, "abrir a porta" e "correr pra você", salientadas em (8), marcam o início da trajetória que é feita pelo casal pelos cômodos da casa. Nessa primeira etapa, é possível observar, graças às expressões "deixo tudo acontecer", "nosso corpo se resvala sem controle pela sala" e "que loucura, que paixão", que o casal troca carícias.

Ao longo do deslocamento, verificamos uma interrupção no percurso, que, em (9), é instanciada pela expressão "paramos no caminho". Nessa pausa, percebemos, com o auxílio 
do trecho "mãos e abraços que doçura, mais abaixo ou na cintura", que a troca de carícias entre o casal se intensifica.

A última etapa que constitui o frame roteiro PREPARAÇÃO PARA O ATO SEXUAL corresponde à chegada do casal ao quarto ("chegamos ofegantes ao destino dos amantes"). Amparados pelas pistas linguísticas disponíveis nos versos da letra, notamos que a ação de chegar ao quarto parece finalizar a preparação para o ato sexual, que, embora não explícito textualmente, pode ser inferido com base no que foi exposto até aqui.

Realizada a descrição desse frame, podemos ilustrar, por meio da figura 2, como ele se constitui:

Figura 2 - Mecanismo de constituência do frame roteiro PREPARAÇÃO PARA O ATO SEXUAL

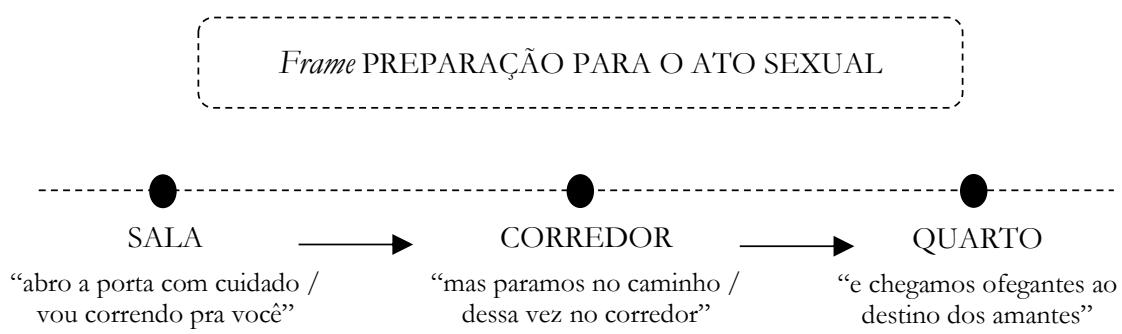

Fonte: elaborada pela autora.

A figura 2 mostra como o frame roteiro PREPARAÇÃO PARA O ATO SEXUAL é formado na letra de canção sob análise: por meio da focalização em ações específicas relacionadas à trajetória feita pelo casal, na casa, nos momentos que antecedem o ato sexual. Esse conjunto de ações, como ilustra a figura, se inicia na sala (quando o homem abre a porta e corre para sua amada), passa pelo corredor (onde as carícias se intensificam) e termina no quarto (onde chegam ofegantes).

\section{Considerações finais}

Com base no que foi exposto na análise, concluímos que os frames, enquanto mecanismos cognitivos, desempenham um papel crucial na construção de sentidos, posto que, graças a eles, as possibilidades de semantização, frente à leitura de uma letra de canção como a que aqui foi explorada, são delimitadas.

Em se tratando da letra "Pelas esquinas da nossa casa", verificamos que o acionamento dos frames conceptuais básicos CASAL, CASA e QUARTO nos leva a perceber que os sentidos que serão construídos estarão associados, de algum modo, a esses três elementos específicos (uma casa, um casal e um quarto) e não a outros. Constatamos, também, que a utilização do item "quarto", responsável por acionar o frame QUARTO, não parece ter sido aleatória, visto que a relação sexual inferida na letra, como dissemos, ocorre no quarto do casal.

Observamos, ademais, que os sentidos decorrentes desses frames foram refinados pelo frame roteiro PREPARAÇÃO PARA O ATO SEXUAL, a partir do qual um conjunto de ações específicas ("abrir a porta", "correr pra você", "parar no caminho" e "chegar") é evocado. 
Tais ações, cumpre relembrar, correspondem ao deslocamento feito pelo casal enquanto trocam carícias peal casa ("sala", "corredor" e "quarto").

Finalmente, frente ao que foi exposto, consideramos que a análise apresentada reforça a ideia de que as construções linguísticas podem ser consideradas como guias de acionamento de frames. Fortalece, também, a noção de que os significados, outrora concebidos como representações mentais abstratas, são, na verdade, de natureza conceptual e não definicional.

\section{Referências}

DUQUE, P. H. Discurso e cognição: uma abordagem baseada em frames. Anpoll, v. 1, n. 39, p. 25-48, 2015.

DUQUE, P. H. De perceptos a frames: cognição ecológica e linguagem. SCRIPTA, v. 21, n. 41, p. $21-45,2017$.

EVANS, V. Cognitive linguistics. Wiley Interdisciplinary Reviews: Cognitive Science, v. 3, n. 2, p. 129-141, 2012.

EVANS, V.; GREEN, M. Cognitive Linguistics: an introduction. Edinburgh: Edinburgh University Press, 2006.

FELDMAN, J. A. From molecule to metaphor: a neural theory of language. Cambridge: The MIT Press, 2006.

JOHNSON, M.; ROHRER, T. We are live creatures: embodiment, American pragmatism, and the cognitive organism. Disponível em:

http://www.neurohumanitiestudies.eu/archivio/blmjohnsonrohrerdraft.pdf. Acesso em: 17 jul. 2019.

LAKOFF, G.; WEHLING, E. The little blue book: the essential guide to thinking and talking democratic. New York: Simon and Schuster, 2012.

MENDES, B. Do giro-lingüístico à hermenêutica: anti-realismo e realismo crítico na narrativa histórica. Disponível em:

http://www.seminariodehistoria.ufop.br/ocs/index.php/snhh/2012/paper/viewFile/1113 /611. Acesso em: 17 dez. 2017.

MERLEAU-PONTY, M. La phénoménologie de la perception. Paris: Gallimard, 1945.

MERLEAU-PONTY, M. Le visible et l'invisible. Paris: Gallimard, 1964.

RICOEUR, P. Soi-même comme un autre. Paris: Seuil, 1990.

SILVEIRA, D. T.; CÓRDOVA, F. P. A pesquisa científica. In: GERHARDT, T. E.; SILVEIRA, D. T. (Org.). Métodos de pesquisa. Porto Alegre: UFGRS, 2009. 